\title{
Expression of P2X7R in breast cancer tissue and the induction of apoptosis by the gene-specific shRNA in MCF-7 cells
}

\author{
CHAO TAN $^{1,2}$, LI HAN $^{1}$, LILI ZOU $^{1}$, CHUNHUA LUO $^{2}$, AIHUA LIU $^{1}$, XIEJING SHENG $^{1}$ and DEE XI ${ }^{1}$ \\ ${ }^{1}$ Institute of Molecular Biology, Medical College, China Three Gorges University, Yichang, Hubei 443002; \\ ${ }^{2}$ First Affiliated Hospital of China Three Gorges University, Yichang, Hubei 443000, P.R. China
}

Received June 28, 2014; Accepted March 5, 2015

DOI: $10.3892 /$ etm.2015.2705

\begin{abstract}
The aim of the present study was to investigate the effects of P2X7R short hairpin (sh)RNA on the proliferation and apoptosis of MCF-7 cells, and to detect the expression of $\mathrm{P} 2 \mathrm{X} 7 \mathrm{R}$ in breast cancer and MCF-7 cells. In order to detect the expression of P2X7R in normal breast and breast cancer tissues, quantitative reverse transcription-polymerase chain reaction (qRT-PCR), western blot analysis and immunohistochemistry were performed. A P2X7-targeted shRNA sequence and a scrambled sequence were inserted into the pLKO.1 expression vector, and MCF-7 cells with stable transfection of P2X7R-shRNA and P2X7R-scrambled shRNA (control) were selected. qRT-PCR was used to detect the mRNA expression levels of $P 2 X 7 R$ in the MCF-7 cells transfected with P2X7R-shRNA and scrambled shRNA. In addition, protein expression levels of P2X7R in the fresh tumor tissues were detected by western blot analysis. An MTT assay was used to detect the proliferation rate at different time points, while flow cytometry was used to detect the growth inhibition and apoptosis rate of the stably transfected MCF-7 cells. P2X7R expression levels in the breast cancer tissues were higher when compared with the normal breast tissue, and a positive correlation was observed with the estrogen receptor $\left(\mathrm{ER}^{+}\right)$, as shown by qRT-PCR, western blot analysis and immunohistochemistry. Plasmids expressing P2X7 gene-specific shRNA and scrambled shRNA were constructed and transfected into MCF-7 cells. The qRT-PCR results revealed lower mRNA expression levels of P2X7 in the P2X7R-shRNA cells when compared with the scrambled shRNA cells. Furthermore, western blot analysis demonstrated that $\mathrm{P} 2 \mathrm{X} 7$ protein was highly expressed in the MCF-7 cells transfected with scrambled shRNA, while low expression was observed in the P2X7R-shRNA-transfected cells. Following transfection of the recombinant plasmids
\end{abstract}

Correspondence to: Professor Li Han, Institute of Molecular Biology, Medical College, China Three Gorges University, 8 Daxue Road, Yichang, Hubei 443002, P.R. China

E-mail: hlyyh@ctgu.edu.cn

Key words: breast cancer, P2X7R, short hairpin RNA into the MCF-7 cells, the proliferation rate in each group was analyzed. The P2X7R-shRNA and KN-62 groups were shown to have significantly reduced rates of proliferation when compared with the normal control group. In addition, flow cytometry revealed that the P2X7R-shRNA and KN-62 groups exhibited a reduced level of cell proliferation and a higher rate of apoptosis. In conclusion, P2X7R was shown to be overexpressed in breast cancer tissues and positively associated with ER expression. A P2X7R-shRNA expression vector effectively inhibited P2X7R expression in MCF-7 breast cancer cells, which subsequently induced cell apoptosis and reduced the levels of cell proliferation. These results indicated that P2X7R may serve as a potential target for breast cancer treatment and prevention.

\section{Introduction}

The P2X family comprises various ligand-gated ion channels, including members of the nicotinic acetylcholine and ionotropic glutamate receptor families. There are seven types of $\mathrm{P} 2 \mathrm{X}$ receptor, namely the $\mathrm{P} 2 \mathrm{X} 1-7$ receptors $(\mathrm{P} 2 \mathrm{X} 1-7 \mathrm{R})(1,2)$. The $\mathrm{P} 2 \mathrm{X} 7$ receptor $(\mathrm{P} 2 \mathrm{X} 7 \mathrm{R})$ is a distinct member of the $\mathrm{P} 2 \mathrm{X}$ subclass, as its downstream signaling is coupled to proinflammatory cascades $(3,4)$. The P2X7R gene is located in chromosome $12 q 24$ and consists of 595 amino acids, with a relative molecular mass of 70-75 kDa. Extracellular ATP and ATP analogs can directly regulate P2X7R, which was initially observed in lymphocytes and macrophages. P2X7R includes a large ecto-domain and two transmembrane domains. The extracellular ring structure, which interacts with ATP, is composed of three $\mathrm{N}$-glycosylation sites, 18-21 lysine residues and a domain with 10 cysteines (5). P2X7R is composed of 595 amino acids, with a highly conserved N-terminal of 395 amino acids in length, and homology with other members of the $\mathrm{P} 2 \mathrm{X}$ receptor family of $35-40 \%$. The intracellular region of P2X7R contains 200 amino acids, which is the longest domain in the $\mathrm{P} 2 \mathrm{X}$ receptor family and includes numerous binding sites for proteins and lipids, as compared with other domains. The motifs exhibit no homology between P2X7R and other proteins, which constituted the molecular basis of its unique function (6). P2X7R is expressed in numerous cell types, the most studied being macrophages and monocytes, and has a key role in regulating cell survival (7). To activate the P2X7R in vitro, extracellular concentrations of ATP in the range of 
$1 \mathrm{mM}$ are necessary, in contrast to concentrations of $\leq 100 \mu \mathrm{M}$ required to activate other $\mathrm{P} 2$ receptors. The ATP molecule binds to and activates $\mathrm{P} 2 \mathrm{X} 7$, resulting in pore formation (7). This pore formation leads to $\mathrm{K}^{+}$efflux from the cell, which is a crucial step in inflammasome assembly. Macrophages treated with ATP in medium containing $\mathrm{KCl}$ (rather than $\mathrm{NaCl}$ ) failed to activate and release IL-1 $\beta$, suggesting that an ATP-induced $\mathrm{K}^{+}$efflux from the cell is necessary for release of mature IL-1 $\beta$, IL- $1 \alpha$ and IL-18. In addition to $\mathrm{K}^{+}$efflux, there is an influx of $\mathrm{Ca}^{2+}$, which is also required for the release of active IL-1 $\beta(7,8)$. Prolonged activation of the P2X7R results in irreversible pore formation and allows the non-selective passage of ions and hydrophilic solutes of up to $900 \mathrm{Da}$, which may result in colloido-osmotic lysis and cell death by apoptosis or necrosis (7). Furthermore, pore formation is hypothesized to facilitate the entry of bacterial products (such as pathogen associated molecular proteins) and extracellular ATP into the cell, which further promotes inflammasome formation (9).

A previous study demonstrated that $\mathrm{P} 2 \mathrm{X} 7 \mathrm{R}$ is overexpressed in breast cancer; thus, is the ideal target for cancer gene therapy (10). In the present study, a pLK0.1-1.1-P2X7R-short hairpin (sh)RNA expression vector was constructed and stably transfected into MCF-7 cell lines to analyze the mechanisms underlying the effects of shRNA specific to P2X7R on the proliferation and apoptosis of MCF-7 cells, and to provide a theoretical foundation for breast cancer gene therapy.

\section{Materials and methods}

Materials and reagents. MCF-7 cell lines were conserved by the Institute of Molecular Biology of China Three Gorges University (Yichang, China). The pLK0.1-1.1-P2X7-shRNA and pLK0.1-1.2-P2X7-scrambled shRNA expression vectors were purchased from Biossci (Hubei) Biotechnologies Co. Ltd. (Wuhan, China). T4 DNA ligase, EcoRI and SacI enzymes, and a quantitative reverse transcription-polymerase chain reaction (qRT-PCR) SYBR Premix Ex Taq II (Tli RNaseH Plus) kit, were purchased from Takara Biotechnology Co. Ltd. (Dalian, China). TRIzol ${ }^{\circledR}$ and Lipofectamine ${ }^{\mathrm{TM}} 2000$ were purchased from Invitrogen Life Technologies (Carlsbad, CA, USA), while goat polyclonal IgG anti-P2X7R (\#ab77413) and rabbit polyclonal IgG anti- $\beta$-actin (\#ab129348) antibodies were purchased from Abcam (Cambridge, UK). RPMI 1640 medium and fetal bovine serum were purchased from Gibco Life Technologies (Beijing, China), and an MTT test kit was purchased from Beijing Probe Biological Technology Co. Ltd. (Beijing, China). An En-vision kit was purchased from Beijing Zhongshan Golden Bridge Biotechnology Co. Ltd. (Beijing, China), while annexin V-fluorescein isothiocyanate and propidium iodide (PI) apoptosis detection kits were purchased from Nanjing Jiancheng Bioengineering Institute, (Nanjing, China). A horseradish peroxidase-labeled goat anti-rabbit IgG $(\mathrm{H}+\mathrm{L})$ was purchased from Thermo Fisher Scientific (Waltham, MA, USA). Approval was obtained from the Ethics Committee of the First Affiliated Hospital of China Three Gorges University (Yichang, China) prior to using the animals for research.

Detecting the expression of $P 2 X 7 R$ in normal breast and breast cancer tissues using $q R T-P C R$. Fresh tissue samples were obtained following surgeries, a portion were immediately stored at $-80^{\circ} \mathrm{C}$, while the remainder were used for pathological detection. Total RNA from the normal breast and breast cancer tissues was extracted using TRIzol ${ }^{\circledR}$. $\beta$-actin was used as a reference. The sequences of the primers used were as follows: P2X7R forward, 5'-ATCGGCTCAACCTCTCCT AC-3' and reverse, 5'-CTGGAGTAAGTCGATGAGGAAG-3' (amplified fragment was $210 \mathrm{bp}$ ); $\beta$-actin forward, 5'-GTG GGGCGCCCCAGGCACCA-3' and reverse, 5'-CTCCTTAAT GTCACGCACGATTTC-3' (amplified fragment was 200 bp). Conditions for RT were $42^{\circ} \mathrm{C}$ for $60 \mathrm{~min}$ and $70^{\circ} \mathrm{C}$ for $5 \mathrm{~min}$, while the qPCR conditions were as follows: Initial denaturation at $94^{\circ} \mathrm{C}$ for $4 \mathrm{~min}$, followed by 40 cycles of $94^{\circ} \mathrm{C}$ for $30 \mathrm{sec}$, $58^{\circ} \mathrm{C}$ for $30 \mathrm{sec}$ and $72^{\circ} \mathrm{C}$ for $30 \mathrm{sec}$, and a final elongation at $72^{\circ} \mathrm{C}$ for $10 \mathrm{~min}$. Approval from the Ethics Committee of First Affiliated Hospital of China Three Gorges University (Hubei, China) and patients was obtained prior to using breast tissues for research.

Detecting the expression of $P 2 X 7 R$ protein in normal breast and breast cancer tissues by western blot analysis. Tissues were removed from a liquid nitrogen tank and ground in a cell lysis buffer (\#ADI-80-1339; Enzo Life Sciences, Inc., Farmingdale, NY, USA). The proteins were extracted and the concentration was determined using a protein extraction kit (\#310004; BESTbio) and an UltraVision Quanto detection system horse radish peroxidase (HRP) 3,3'-diaminobenzidine (DAB) (\#TL-060-QHD; Thermo Fisher Scientific, Waltham, MA, USA), according to the manufacturer's instructions. Western blot analysis was conducted following the instructions of Sambrook and Russell (11) and the antibody-antigen complex was visualized with an enhanced chemiluminescence western blotting detection kit (GE Healthcare Life Sciences, Chalfont, UK).

Detecting the expression of $P 2 X 7 R$ protein in normal breast and breast cancer tissues using immunohistochemistry. Tissues were fixed in formalin and sliced following embedding in paraffin. Immunohistochemical analysis of P2X7R in breast cancer tissue was then performed. First, tissue sections were deparaffinized and rehydrated. Sections were then rinsed in phosphate-buffered saline with Tween-20 (PBST) and blocked with $3 \%$ peroxide-methanol at room temperature for endogenous peroxidase ablation. Sections were incubated with Ultra V Block (TA-125-PBQ; Lab Vision Corporation, Fremont, CA, USA) for 5 min to block nonspecific background staining. Ultra V Block agent was discarded and sections incubated with an anti-P2X7R antibody (\#ab77413; Abcam) diluted in PBS for $2 \mathrm{~h}$ at $37^{\circ} \mathrm{C}$. Rinse in PBST three times (5 min per rinse). Apply Primary Antibody Amplifier Quanto (\#TL-125-QHD; Thermo Fisher Scientific) and incubate for 10 min. Rinse three times ( 5 min) in PBST. Apply HRP Polymer Quanto (\#TL-125-QHD) and incubate for $10 \mathrm{~min}$. Sections were subsequently visualized with $\mathrm{DAB}$ at room temperature without light for $5 \mathrm{~min}$. Finish colouration with the distilled water. Counterstaining was performed using hematoxylin and a coverslip with a permanent mounting media.

Construction of an shRNA expression vector. shRNA sequences were synthesized by Hubei Biossci Biotechnology Co., Ltd. 


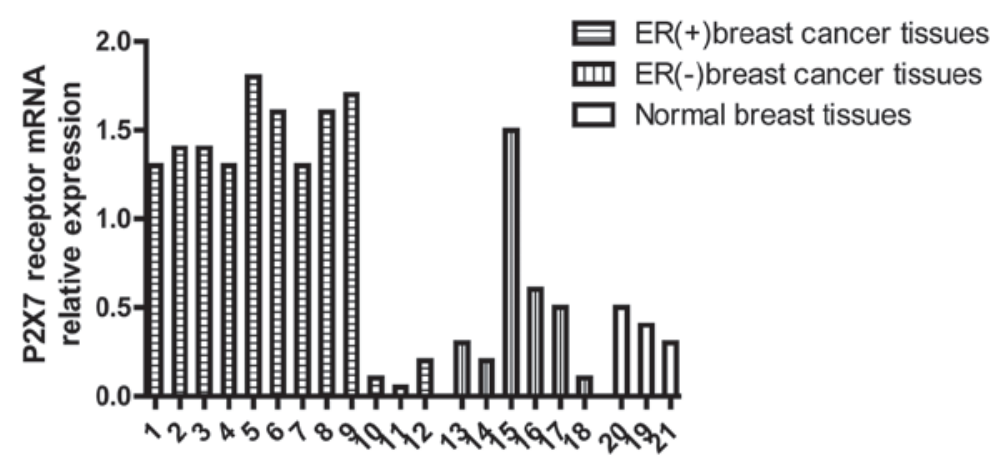

Figure 1. Quantitative reverse transcription-polymerase chain reaction was used to detect the mRNA expression levels of P2X7R in normal breast and breast

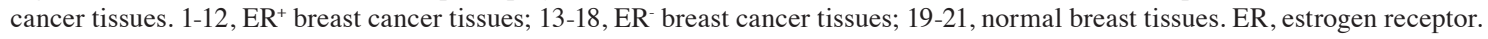

Table I. Expression status of P2X7R mRNA in normal breast and breast cancer tissues.

\begin{tabular}{lccc}
\hline Pathology & Cases $(\mathrm{n})$ & Positive & Negative \\
\hline Normal & 3 & 0 & 3 \\
ER $^{+}$cancer & 12 & 9 & 3 \\
ER cancer & 6 & 1 & 5 \\
Total & 21 & $47.6 \%$ & $52.4 \%$ \\
\hline
\end{tabular}

ER, estrogen receptor.

Table II. Expression status of P2X7R protein in normal breast and breast cancer tissues.

\begin{tabular}{lccc}
\hline Pathology & Cases (n) & Positive & Negative \\
\hline Normal & 3 & 0 & 3 \\
ER & 12 & 9 & 3 \\
ER tumor & 6 & 1 & 5 \\
Total & 21 & $47.6 \%$ & $52.4 \%$ \\
\hline
\end{tabular}

ER, estrogen receptor.

Table III. Expression status of P2X7R protein in pathological samples of normal breast and breast cancer tissues.

\begin{tabular}{lccc}
\hline Pathology & Cases (n) & Positive & Negative \\
\hline Normal & 20 & 0 & 20 \\
ER $^{+}$tumor & 20 & 17 & 3 \\
ER tumor & 20 & 5 & 15 \\
Total & 60 & $36.7 \%$ & $63.3 \%$ \\
\hline
\end{tabular}

ER, estrogen receptor.

(Wuhan, China). According to the P2X7R mRNA sequence in GenBank, two 19-bp targeting sequences were designed using the online design software of Ambion siRNA Target Finder

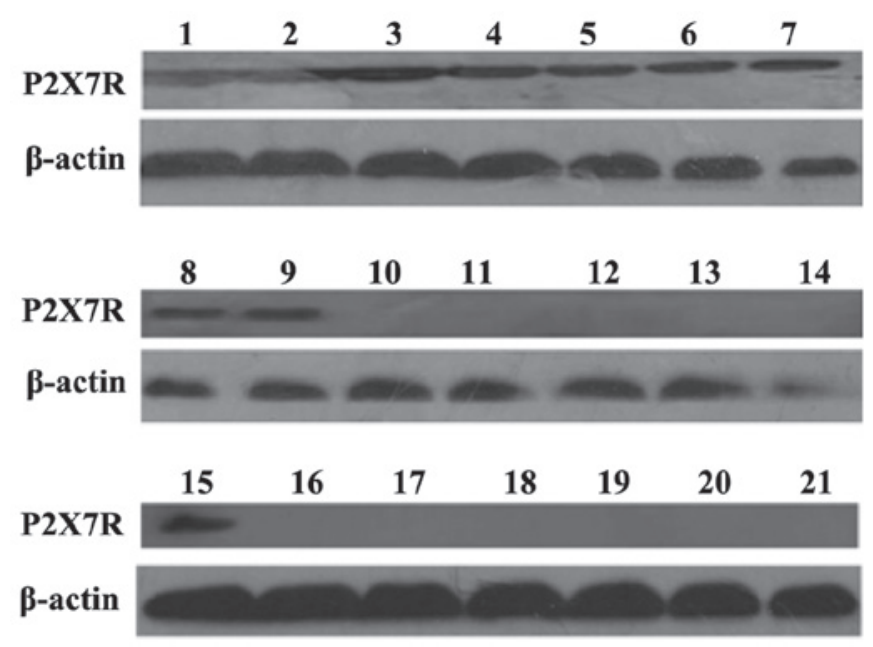

Figure 2. Western blot analysis was used to detect the protein expression of P2X7R in normal breast and breast cancer tissues. Lanes 1-12, $\mathrm{ER}^{+}$breast cancer tissues; 13-18, ER breast cancer tissues; 19-21, normal breast tissues. ER, estrogen receptor.

and GenScript siRNA Target Finder (http://www.genscript. com/index.html). The nucleotide sequences were as follows (underlined sequences were targeted): P2X7-shRNA forward, GATCCCC GGATCCAGAGCATGAATTA TTCAAGAGA TAATTCATGCTCTGGATCC TTTTTGGAAA, and reverse, AATTTTTCCAAAAA GGATCCAGAGCATGAATTA TCT CTTGAA TAATTCATGCTCTGGATCC GGG; scrambled shRNA forward, GATCCCC TTCTCCGAACGTGTCACG T TTCAAGAGA ACGTGACACGTTCGGAGAA TTTTTG GAAA, and reverse, AATTTTTCCAAAAA TTCTCCGAA CGTGTCACGT TCTCTTGAA ACGTGACACGTTCGG AGAA GGG. Escherichia coli BL21 (DE3) cells from the Institute of Molecular Biology, Medical College, China Three Gorges University (Yichang, Hubei, China) were transformed with pLK0.1-1.1-P2X7-shRNA and pLK0.1-1.2-P2X7-scrambled shRNA, which was confirmed by DNA sequencing (Shanghai Sangon Biotechnology Co., Ltd., Shanghai, China).

Detecting the cell proliferation rate of each group with an MTT assay. Cells from each group at a logarithmic phase, which included the pLK0.1-1.1-P2X7-shRNA, pLK0.1-1.2-P2X7-scrambled shRNA, KN-62 CaM kinase inhibitor (\#BML-EI230-0001; Enzo Life Sciences) treatment 
A

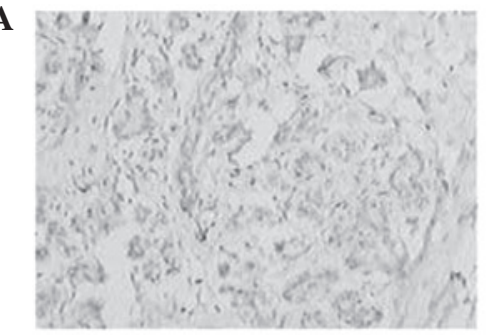

C

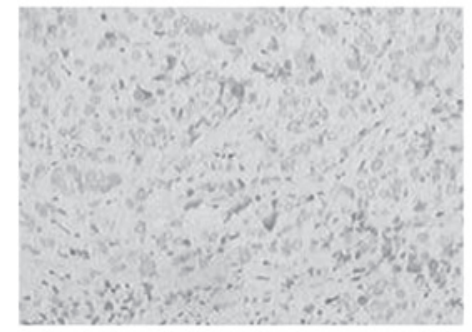

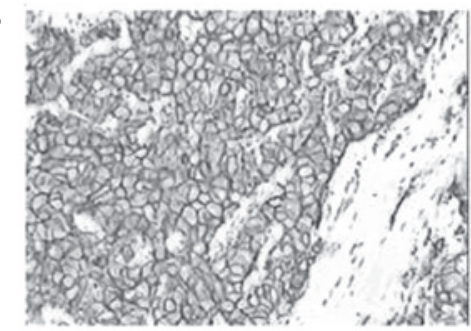

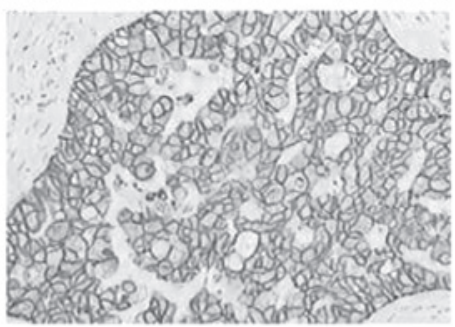

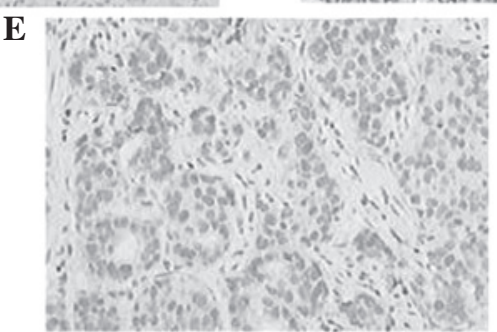

Figure 3. Immunohistochemistry analysis shows the protein expression of P2X7R in normal breast and breast cancer tissues. (A) Normal, P2X7R(-); (B) ER ${ }^{+}$ tumor, P2X7R(+); (C) ER+ tumor, P2X7R(-); (D) ER- tumor, P2X7R(+); and (E) ER' tumor, P2X7R(-). ER, estrogen receptor.

Table IV. mRNA expression levels of P2X7R in each group, as determined using quantitative reverse transcription-polymerase chain reaction.

\begin{tabular}{lc} 
Group & P2X7R mRNA \\
\hline P2X7R-scrambled shRNA & $0.42 \pm 0.27$ \\
P2X7R-shRNA & $0.23 \pm 0.14^{\mathrm{a}}$ \\
Control & $0.47 \pm 0.21$
\end{tabular}

${ }^{\mathrm{a}} \mathrm{P}<0.05$, vs. control group. Data are presented as mean \pm standard deviation. shRNA, short hairpin RNA.

and normal MCF-7 groups, were inoculated into 96-well plates (100 $\mu 1$ per well). KN-62 is an inhibitor of P2X7R, and was used as the control against shP2X7R to determined whether the shP2X7R was active. Following adherence of the cells, MTT ( $200 \mu \mathrm{g} / \mathrm{ml}$; prepared by serum-free RPMI-1640 medium) was added to the wells and the cells were inoculated at $37^{\circ} \mathrm{C}$ for $4 \mathrm{~h}$. The supernatant was removed and $150 \mu 1$ dimethyl sulfoxide was added to each well. Finally, after shaking for $20 \mathrm{~min}$ at room temperature, the optical density was detected at $490 \mathrm{~nm}$ using a Multiskan Spectrum (Thermo Fisher Scientific). Experiments were repeated three times.

Detecting the cell apoptosis rate in each group by flow cytometry. Stably transfected cells (recombinant plasmid pLK0.1-1.1-P2X7-shRNA and pLK0.1-1.2-P2X7-scrambled shRNA) were digested by Trypsin (\#ROO1100, Invitrogen),

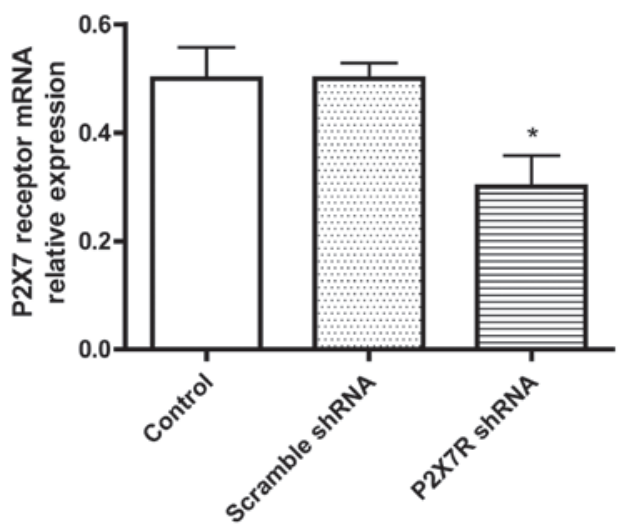

Figure 4. Quantitative reverse transcription-polymerase chain reaction was used to detect the mRNA expression of $\mathrm{P} 2 \mathrm{X} 7 \mathrm{R}$ in each group. ${ }^{*} \mathrm{P}<0.05$, vs. control group. shRNA, short hairpin RNA.

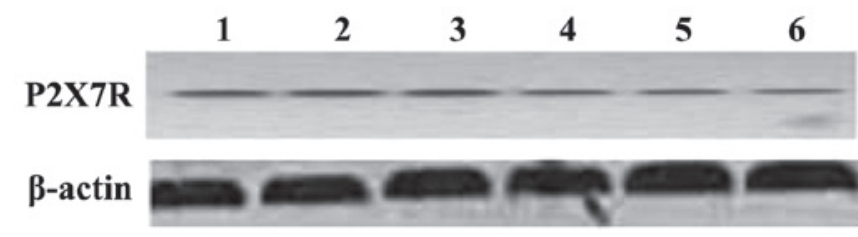

Figure 5. Western blot analysis was used to detect the protein expression of P2X7R in each group. 1, MCF-7 control; 2 and 3, P2X7R-scrambled shRNA; 4-6, P2X7R-shRNA. shRNA, short hairpin RNA.

washed with phosphate-buffered saline (PBS) and fixed in 75\% ethanol at $4^{\circ} \mathrm{C}$ overnight. Cells were collected and centrifugated at $1,500 \mathrm{x}$ g for $5 \mathrm{~min}$ at $4^{\circ} \mathrm{C}$ using an Eppendorf 5810R 
Table V. Cell growth at the different time points following plasmid transfection.

\begin{tabular}{lllll}
\hline Group & $0 \mathrm{~h}$ & $24 \mathrm{~h}$ & $48 \mathrm{~h}$ & $72 \mathrm{~h}$ \\
\hline MCF-7 control & $1 \pm 2.31$ & $1.34 \pm 2.81$ & $2.27 \pm 2.23$ & $3.39 \pm 3.05$ \\
P2X7R-scrambled shRNA & $1 \pm 2.74$ & $1.57 \pm 2.82$ & $2.37 \pm 2.68$ & $3.30 \pm 3.15$ \\
P2X7R shRNA & $1 \pm 2.03^{\mathrm{a}}$ & $1.35 \pm 2.49^{\mathrm{a}}$ & $1.53 \pm 1.91^{\mathrm{a}}$ & $2.07 \pm 2.13^{\mathrm{a}}$ \\
KN-62 & $1 \pm 2.06^{\mathrm{a}}$ & $1.36 \pm 2.85^{\mathrm{a}}$ & $1.50 \pm 1.87^{\mathrm{a}}$ & $1.84 \pm 2.39^{\mathrm{a}}$ \\
\hline
\end{tabular}

${ }^{\mathrm{a}} \mathrm{P}<0.05$, vs. control group. Data are presented as mean \pm standard deviation $\left(10^{4}\right.$ cells $\left./ \mathrm{ml}\right)$. shRNA, short hairpin RNA.

Table VI. Apoptosis rate in each group following transfection (\%).

\begin{tabular}{lrrr}
\hline Group & $24 \mathrm{~h}$ & $48 \mathrm{~h}$ & $72 \mathrm{~h}$ \\
\hline MCF-7 control & $2.14 \pm 1.05$ & $3.05 \pm 1.48$ & $2.95 \pm 1.35$ \\
P2X7R-scrambled shRNA & $4.05 \pm 1.26$ & $4.23 \pm 1.41$ & $4.11 \pm 1.56$ \\
P2X7R-shRNA & $22.58 \pm 1.59^{\mathrm{a}}$ & $35.92 \pm 2.14^{\mathrm{a}}$ & $24.51 \pm 1.48^{\mathrm{a}}$ \\
\hline
\end{tabular}

${ }^{\mathrm{a}} \mathrm{P}<0.05$, vs. control group. Data are presented as mean \pm standard deviation. shRNA, short hairpin RNA.

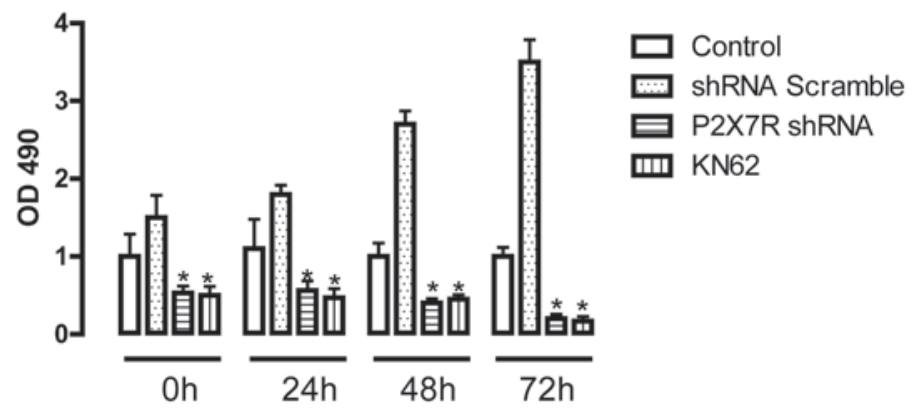

Figure 6. An MTT assay was used to assess cell proliferation in each group at different time points. "P<0.05, vs. control group. OD, optical density; shRNA, short hairpin RNA.
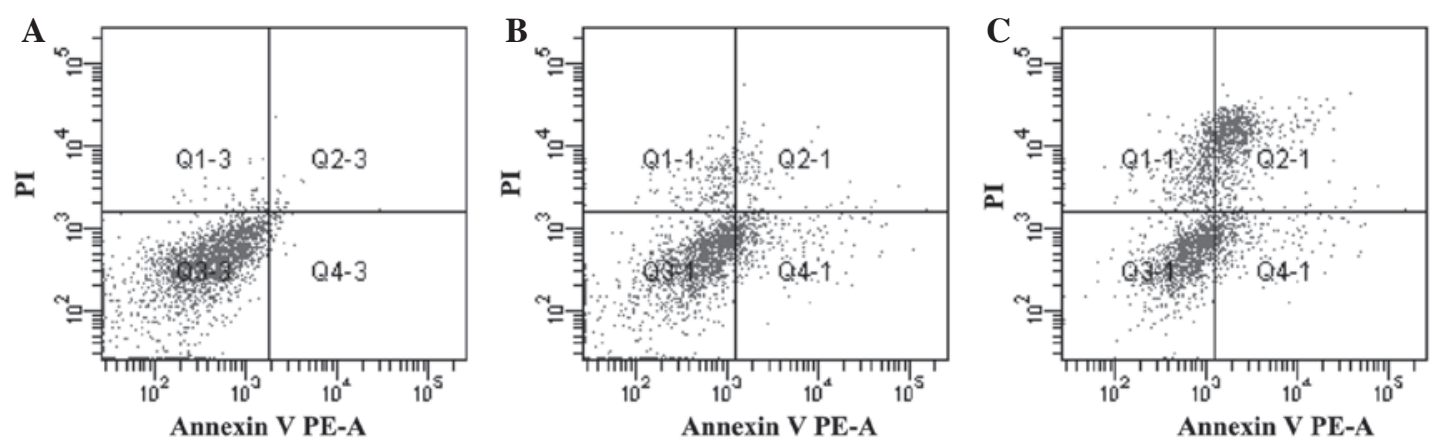

Figure 7. Apoptosis rate in each group following transfection, as measured by flow cytometry. (A) MCF-7 cells (control); (B) P2X7R-scrambled shRNA; (C) P2X7R-shRNA. PI, propidium iodide; shRNA, short hairpin RNA.

centrifuge (Eppendorf, Hamburg, Germany), then rinsed with ice-cold PBS. After washing three times and dyeing with $\mathrm{PI}$, the cells were protected from light for $5 \mathrm{~min}$. Cells were centrifugated at $1,000 \mathrm{x}$ g for $5 \mathrm{~min}$ at $4^{\circ} \mathrm{C}$. Subsequently, $300 \mu 1 \mathrm{PBS}$ was added and cells were counted using an EPICS XL-4 flow cytometer (Beckman Coulter, Brea, CA, USA), with normal MCF-7 cells used as a control.
Statistical analysis. All statistical analyses were performed using GraphPad Prism software (GraphPad Software, Inc., La Jolla, CA, USA). Values are expressed as the mean \pm standard error. Pair-wise comparisons were performed using Student's $t$-test (two-tailed). Multiple-group comparisons were performed using one-way analysis of variance with Bonferroni's post test. $\mathrm{P}<0.05$ was considered to indicate a statistically significant difference. 


\section{Results}

$m R N A$ and protein expression of $P 2 X 7 R$ in normal breast and breast cancer tissues. A total of 21 breast samples were selected from the First Affiliated Hospital of China Three Gorges University. Analysis from the pathological sections revealed three breast samples were normal breast tissue, 12 breast samples were estrogen receptor positive $\left(\mathrm{ER}^{+}\right)$ breast cancer tissues and six samples were ER negative (ER $\left.{ }^{-}\right)$ breast cancer tissues. Expression of P2X7R at the mRNA level was observed in nine of the $\mathrm{ER}^{+}$breast cancer tissues and one of the ER ${ }^{-}$breast cancer tissues (Table I and Fig. 1; $\mathrm{P}<0.05)$.

The 21 breast tissue samples were preserved in liquid nitrogen and used for the detection of P2X7R at the protein level. Western blot analysis indicated that nine $\mathrm{ER}^{+}$breast cancer tissue samples and one ER- breast cancer tissue sample expressed P2X7R at the protein level (Table II and Fig. 2; $\mathrm{P}<0.05)$.

Immunohistochemistry analysis of the expression status of P2X7R protein in normal breast and cancerous tissues. In total, 60 pathological samples were obtained from the First Affiliated Hospital of China Three Gorges University, including 20 normal breast tissues, $20 \mathrm{ER}^{+}$breast cancer tissues and $20 \mathrm{ER}^{-}$breast cancer tissues. The results revealed that there was no expression of $\mathrm{P} 2 \mathrm{X} 7 \mathrm{R}$ protein in normal breast tissues; however, $17 \mathrm{ER}^{+}$and $5 \mathrm{ER}^{-}$breast cancer tissues exhibited P2X7R protein expression (Table III and Fig. 3; $\mathrm{P}<0.01)$.

$P 2 X 7 R$ expression in the MCF-7 cell lines. A recombinant plasmid was transfected into MCF-7 cell lines and the cells were collected after $48 \mathrm{~h}$ for qRT-PCR. The results demonstrated that the mRNA expression of P2X7R in the P2X7R-shRNA group was significantly lower when compared with the scrambled shRNA and normal MCF-7 control group $(\mathrm{P}<0.05)$; however, there was no statistically significant difference between the P2X7R-scrambled shRNA group and normal MCF-7 cell control group (Table IV and Fig. 4; P>0.05).

In addition, western blot analysis was used to assess the protein expression in the MCF-7 cell lines following recombinant plasmid transfection for $48 \mathrm{~h}$. The results revealed that the expression of P2X7R in the P2X7R-shRNA group was significantly lower compared with the P2X7R-scrambled shRNA and the normal MCF-7 cell control groups (Fig. 5; $\mathrm{P}<0.05)$.

Cell proliferation rates in each group. An MTT assay revealed that the P2X7R-shRNA and KN-62 (antagonist of P2X7R) positive control groups exhibited a markedly reduced proliferation rate compared with the P2X7R-scrambled shRNA or normal MCF-7 cell groups at $0,24,48$ and $72 \mathrm{~h}(\mathrm{P}<0.05)$. No statistically significant difference was observed between the P2X7R-scrambled shRNA and control groups $(\mathrm{P}>0.05)$. The results indicated that the reduced expression of $\mathrm{P} 2 \mathrm{X} 7 \mathrm{R}$ in the P2X7R-shRNA and KN-62 MCF-7 cell lines inhibited the development of the MCF-7 cell lines (Table V and Fig. 6).
Apoptosis rates in each group. Apoptosis rates in the P2X7R-shRNA group significantly increased when compared with the P2X7R-scrambled shRNA group and the MCF-7 cell control group. The apoptosis rate was most evident at the $48 \mathrm{~h}$ time point (Table VI and Fig. 7; $\mathrm{P}<0.05$ ).

\section{Discussion}

Breast cancer is one of the most common types of malignant tumor and is a serious threat to the health of the patient (12). A previous study found that there was no expression of P2X7R in normal breast tissues; however, P2X7R was overexpressed in breast cancer tissue (13). Furthermore, P2X7R can be activated due to a high ATP concentration in the tumor interstitium, as compared with normal tissues, which is implicated in promoting proliferation and the development of breast cancer (14).

$\mathrm{P} 2 \mathrm{X} 7 \mathrm{R}$ is a member of the $\mathrm{P} 2 \mathrm{X}$ family and has numerous biological functions, involving cell signal transduction, the secretion of cytokines and the survival and development of cells. P2X7R is able to induce cells to undergo apoptosis or necrosis via two mechanisms. Firstly, following integration with ATP, P2X7R induces the production of membrane pores of dissolving cells, resulting in necrosis in the $\mathrm{Ca}^{2+}$ independent pathway. Secondly, sustained ATP stimulation activates P2X7R, which generates numerous $\mathrm{Ca}^{2+}$ ions to enter the cells, resulting in apoptosis. Secondly, the sustained ATP stimulation activates $\mathrm{P} 2 \mathrm{X} 7 \mathrm{R}$, which causes a large amount of $\mathrm{Ca}^{2+}$ ions to enter the cells, resulting in apoptosis. In addition, the activation of P2X7R can exhaust the intracellular $\mathrm{K}^{+}$ stores and activate the aspartic acid cysteine specific kinase, interleukin-1 $\beta$ converting enzyme, which is involved in apoptosis (15).

shRNA is a sequence of RNA that forms a tight hairpin turn that can be used to silence target gene expression via slicing; the latter is named small interfering RNA (siRNA). siRNA is composed of 21-23 nucleotides and can specifically combine with an RNA-induced silencing complex to degrade target mRNA (16). An expression vector is used to import shRNA into the cell, while a U6 promoter generates the expression of shRNA and transmits the expression to offspring (17). The shRNA technique is an efficient and specific gene sealing technique that can remove abnormal mRNA and resist the invasion of external factors.

In conclusion, breast cancer is a common malignant type of tumor, and P2X7R has been found to be overexpressed in breast cancer cell lines and tissues. Using PCR, western blot analysis and flow cytometry, the present study demonstrated that the expression of P2X7R in the P2X7R-shRNA group was significantly lower compared with the P2X7R-scrambled shRNA and normal MCF-7 cell control groups at an mRNA and protein level. In addition, an MTT assay indicated that P2X7R played an important role in the proliferation and apoptosis of breast cancer cells; however, the specific molecular mechanism remains unclear. Future research should focus on elucidating the expression and function of P2X7R in breast cancer and investigate the specific molecular mechanism underlying the inhibition of tumor cell development, which may provide a novel theoretical basis for the diagnosis and treatment of breast cancer. 


\section{Acknowledgements}

This study was supported by grants from the National Science Foundation of China (no. 81201766), the Nature Science Foundation of Hubei Province, China (no. 2009CDZ024 and 2014CFB307), the Scientific Research Innovation Foundation of China Three Gorges University (no. 2011CX059) and the Scientific Research Cultivation Foundation of China Three Gorges University (no. 2012PY049).

\section{References}

1. Díez-Zaera M, Díaz-Hernández JI, Hernández-Álvarez E, et al: Tissue-nonspecific alkaline phosphatase promotes axonal growth of hippocampal neurons. Mol Biol Cell 22: 1014-1024, 2011.

2. Agrawal A and Gartland A: P2X7 receptors: Role in bone cell formation and function. J Mol Endocrinol 54: R75-R88, 2015.

3. North RA: Molecular physiology of P2X receptors. Physiol Rev 82: 1013-1067, 2002.

4. Di Virgilio F: P2X receptors and inflammation. Curr Med Chem 22: 866-877, 2015

5. Gartland A, Skarratt KK, Hocking LJ, Parsons C, Stokes L, Jørgensen NR, Fraser WD, Reid DM, Gallagher JA and Wiley JS: Polymorphisms in the $\mathrm{P} 2 \mathrm{X} 7$ receptor gene are associated with low lumbar spine bone mineral density and accelerated bone loss in post-menopausal women. Eur J Hum Genet 20: 559-564, 2012

6. Gutiérrez-Martín Y, Bustillo D, Gómez-Villafuertes R, et al: P2X7 receptors trigger ATP exocytosis and modify secretory vesicle dynamics in neuroblastoma cells. J Biol Chem 286 11370-11381, 2011.
7. Ferrari D, Pizzirani C, Adinolfi E, et al: The P2X7 receptor: A key player in IL-1 processing and release. J Immunol 176: 3877-3883, 2006

8. MacKenzie A, Wilson HL, Kiss-Toth E, et al: Rapid secretion of interleukin-1beta by microvesicle shedding. Immunity 15 : 825-835, 2001.

9. Pelegrin P and Surprenant A: The P2X(7) receptor-pannexin connection to dye uptake and IL-1beta release. Purinergic Signal 5: 129-137, 2009.

10. Nazıroğlu $M$, Tokat $S$ and Demirci $S$ : Role of melatonin on electromagnetic radiation-induced oxidative stress and $\mathrm{Ca}^{2+}$ signaling molecular pathways in breast cancer. J Recept Signal Transduct Res 32: 290-297, 2012.

11. Sambrook J and Russell DW; Translated by Huang PT. Molecular Cloning: A Laboratory Manual. (3rd Edition). Cold Spring Harbor Laboratory Press, NY. pp1474-1480, 2001.

12. Oran ES, Yankol Y, Soybir GR, et al: Distinct postsurgical management in young and elderly breast cancer patients results in equal survival rates. Asian Pac J Cancer Prev 15: 7843-7847, 2014.

13. Iversen A, Thune I, McTiernan A, et al: Ovarian hormones and reproductive risk factors for breast cancer in premenopausal women: The Norwegian EBBA-I study. Hum Reprod 26: 1519-1529, 2011.

14. Uzgiris EE: A cell-surface polymer reptation mechanism for tumor transendothelial transport of macromolecules. Technol Cancer Res Treat 7: 257-268, 2008.

15. Qu Y, Misaghi S, Newton K, et al: Pannexin-1 is required for ATP release during apoptosis but not for inflammasome activation. J Immunol 186: 6553-6561, 2011.

16. Iyer AK, Singh A, Ganta S and Amiji MM: Role of integrated cancer nanomedicine in overcoming drug resistance. Adv Drug Deliv Rev 65: 1784-1802, 2013.

17. Cai Y, Wang H, Hou Y, et al: Study on the effect of Klotho gene interferred by plasmid-mediated short hairpin RNA (shRNA) on sinoatrial node pacing channel gene. Sheng Wu Yi Xue Gong Cheng Xue Za Zhi 30: 588-591, 2013 (In Chinese). 